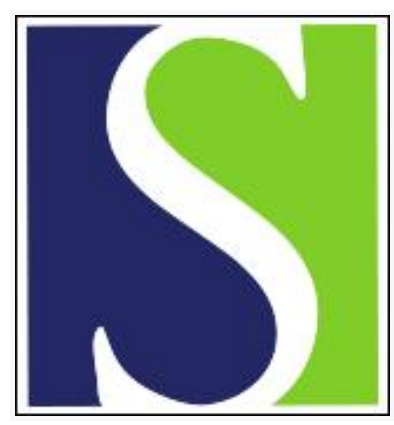

Scand J Work Environ Health 2011;37(3):244-252

https://doi.org/10.5271/sjweh.3129

Published online: 03 Nov 2010, Issue date: May 2011

Frequency weightings of hand-transmitted vibration for predicting vibration-induced white finger

by Bovenzi M, Pinto I, Picciolo F, Mauro M, Ronchese F

Affiliation: Clinical Unit of Occupational Medicine, Department of Reproductive, Developmental and Public Health Sciences, University of Trieste, Centro Tumori, Via della Pietà 19, 34129 Trieste, Italy. bovenzi@units.it

Refers to the following texts of the Journal: 1989;15(5):339-344 1986;12(4):293-295 1986;12(4):338-342

The following article refers to this text: 2015;41(3):247-258

Key terms: exposure-response relationship; frequency weighting; hand-transmitted vibration; longitudinal study; vascular disorder; vibration magnitude; VWF; white finger

This article in PubMed: www.ncbi.nlm.nih.gov/pubmed/21046061

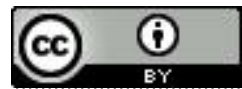




\title{
Frequency weightings of hand-transmitted vibration for predicting vibration- induced white finger
}

\author{
by Massimo Bovenzi, MD, ${ }^{1}$ Iole Pinto, MSc, ${ }^{2}$ Francesco Picciolo, MSc, ${ }^{2}$ Marcella Mauro, MD, ${ }^{1}$ Federico \\ Ronchese, $M D^{1}$
}

\begin{abstract}
Bovenzi M, Pinto I, Picciolo F, Mauro M, Ronchese F. Frequency weightings of hand-transmitted vibration for predicting vibration-induced white finger. Scand J Work Environ Health. 2011;37(3):244-252. doi:10.5271/sjweh.3129
\end{abstract}

\begin{abstract}
Objective The aim of this study was to investigate the performance of four frequency weightings for handtransmitted vibration to predict the incidence of vibration-induced white finger (VWF).

Methods In a longitudinal study of vibration-exposed forestry and stone workers $(\mathrm{N}=206)$, the incidence of VWF was related to measures of vibration exposure expressed in terms of 8-hour frequency-weighted energyequivalent root-mean-square (rms) acceleration magnitude $[A(8)]$ and years of follow-up. To calculate $A(8)$, the rms acceleration magnitudes of vibration were weighted by means of four frequency weightings: (i) $W_{\mathrm{h}}$ (the frequency weighting specified in ISO 5349-1:2001); (ii) $W_{\mathrm{h}-\mathrm{bl}}$ (the band-limiting component of $W_{\mathrm{h}}$ ); (iii) $W_{\mathrm{hf}}$ (a frequency weighting based on finger vibration power absorption); and (iv) $W_{\mathrm{hT}}$ (a frequency weighting based on a Japanese study of VWF prevalence). The relations of VWF to alternative measures of vibration exposure were assessed by the generalized estimating equations (GEE) method to account for the within-subject dependency of the observations over time.
\end{abstract}

Results Data analysis with a GEE logistic model and a measure of statistical fit suggested that calculating $A(8)$ by weighting the tool rms accelerations with $W_{\mathrm{h}-\mathrm{ll}}$ gave better predictions of the cumulative incidence of VWF than the other alternative measures of daily vibration exposure. Values of $A(8)$ derived from the currently recommended ISO frequency weighting $W_{\mathrm{h}}$ produced poorer predictions of the incidence of VWF than those obtained with frequency weightings $W_{\mathrm{hf}}$ or $W_{\mathrm{hT}}$.

Conclusions This prospective cohort study suggests that measures of daily vibration exposure which give relatively more weight to intermediate and high frequency vibration are more appropriate for assessing the probability of VWF.

Key terms exposure-response relationship; longitudinal study; vascular disorders; vibration magnitude; VWF.

Occupational exposure to hand-transmitted vibration is associated with increased risk of developing a secondary form of Raynaud's phenomenon called vibration-induced white finger (VWF). The exposure-response relationship for this vascular disorder is not yet fully known. In international standard ISO 5349-1:2001 (1), daily exposure to hand-transmitted vibration is expressed in terms of the 8-hour frequency-weighted energy-equivalent acceleration $[A(8)]$. In this ISO standard, the root-mean-square (rms) accelerations of vibratory tools are weighted by means of a frequency weighting (called $W_{\mathrm{h}}$ ), which assumes that vibration-induced adverse health effects are inversely related to the frequency of vibration between $16-1250 \mathrm{~Hz}$.

Annex C to ISO 5349-1 proposes an almost linear relation between $A(8)$ and the number of exposure years for a probability of VWF in $10 \%$ of a vibration-exposed population (1). Over the past decades, several epidemiological studies have reported discrepancies between the observed occurrence of VWF among various vibrationexposed worker groups and that predicted by the ISO standard. Both over- and underestimation of VWF risk have been reported by investigators involved in epidemiological research (2-6). Moreover, the findings of experimental investigations have suggested that the frequency weighting $W_{\mathrm{h}}$ (given in ISO 5349-1) does not seem to reflect the frequency-dependence of the physiological or biodynamic responses of the fingers to vibration (7-9).

In addition to the ISO weighting method, a set of candidate frequency weightings for the evaluation of workplace vibration exposures is currently under

1 Clinical Unit of Occupational Medicine, Department of Reproductive, Developmental and Public Health Sciences, University of Trieste, Italy.

2 Physical Agents Laboratory, Department of Prevention, Local Health Unit 7, National Health Service, Siena, Italy. 
consideration in the working group on hand-transmitted vibration (WG 3) of the ISO technical committee ISO/ TC 108/SC 4 concerning human exposure to mechanical vibration and shock (10). These candidate frequency weightings are based on the findings of either epidemiological studies of vibration-exposed workers or biodynamic investigations of vibration power absorption in the fingers $(9,11-13)$.

The aim of this study was to investigate the performance of four alternative frequency weightings to predict the incidence of VWF in a cohort of forestry and stone workers recruited in a four-year research project supported by the European Union (EU) and entitled Risks of Occupational Vibration Injuries (VIBRISKS) (14).

\section{Methods}

\section{Subjects and medical investigations}

The cohort included 206 vibration-exposed workers (185 forestry operators and 21 stone workers) who were unaffected with VWF symptoms at the initial survey conducted between October 2003 and February 2004. Of these workers, $146(70.9 \%)$ participated in three followup surveys, and 60 (29.1\%) participated in either one or two follow-up investigations over the calendar period autumn 2004 to winter 2007. All subjects continued to work with vibratory tools during the follow-up period.

All subjects gave signed informed consent to participate in the study, which was approved by the local health authorities. A complete description of the cohort and the study design have been reported earlier $(11,12)$.

The diagnosis of VWF was based on the findings of a medical interview assisted by color charts. The criteria for the anamnestic diagnosis of VWF, according to the Stockholm Workshop 1994 scale and the procedure for the administration of color charts has been described in detail elsewhere $(12,15,16)$. A clinical diagnosis of white finger was considered positive when the subject, in addition to subjective symptoms, displayed the welldemarcated blanching of the fingers indicated in the color charts. Individuals reporting white finger symptoms at the medical interview that were not supported by color charts were not classified as cases of VWF.

\section{Measurement and evaluation of vibration exposure}

Vibration generated by the tools used by the forestry and stone workers was measured in the field under real operating conditions. Vibration measurements were made at the cross-sectional survey in winter 2004; no changes in either the type of tools or operating conditions occurred over the follow-up period for both the forestry and the stone workers. Vibration was measured in three orthogonal directions $(x, y, z)$ according to the procedure in international standard ISO 5349-1 (1). The vibration time histories were stored in the digital recorder DAT HEIM DATaRec-A80 (Müller-BBM VibroAkustik Systeme GmbH, Planegg, Germany) and then analyzed in the laboratory by the signal analyzer IMC FAMOS (IMC DataWorks LLC, Madison, WI, USA). Vibration magnitudes were expressed as rms acceleration over the frequency range defined in international standard ISO 8041:2005 (1-4000 Hz) (17).

Acceleration magnitudes were weighted using the frequency weightings displayed in figure 1 (10): (i) $W_{\mathrm{h}}$ is the frequency weighting specified in ISO 5349-1 (1); (ii) $W_{\mathrm{h}-b \mathrm{l}}$ is the band-limiting component of $W_{\mathrm{h}}(17)$; (iii) $W_{\mathrm{hf}}$ is a frequency weighting based on biodynamic studies of finger vibration power absorption $(9,10)$; (iv) $W_{\mathrm{hT}}$ is a frequency weighting based on a Japanese study of VWF prevalence in worker groups investigated from 1957-1977 (10, 13).

The root-sum-of-squares (also called the vibration total value) of the rms acceleration frequency weighted according to $W_{\mathrm{h}}, W_{\mathrm{h}-\mathrm{bl}}, W_{\mathrm{hf}}$, or $W_{\mathrm{hT}}\left[a_{\mathrm{hv}}\left(W_{\mathrm{hi}}\right)\right]$ for the $x$-,

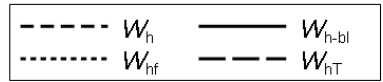

Figure 1. Comparison of frequency weighting functions for hand-transmitted vibration. [ $W_{\mathrm{h}}=$ frequency weighting as defined in IS0 5349-1:2001 (1); $W_{\mathrm{h}-\mathrm{bl}}=$ the band-limiting component of $W_{\mathrm{h}}(17) ; W_{\mathrm{hf}}=$ a frequency weighting based on finger vibration power absorption $(9,10) ; W_{\mathrm{hT}}=\mathrm{a}$ frequency weighting based on a Japanese study of vibration-induced white finger (VWF) prevalence $(10,13)$.]

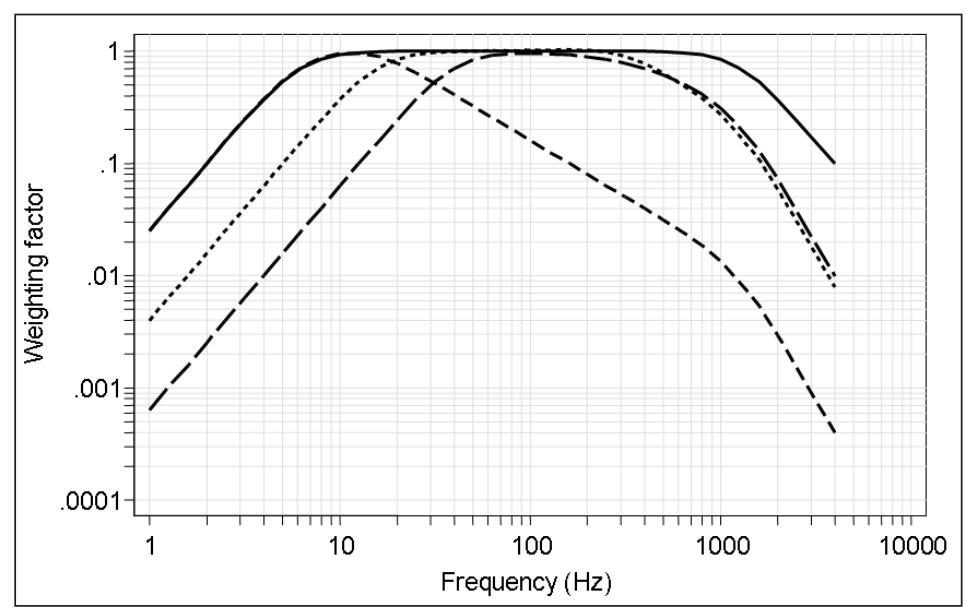

Scand J Work Environ Health 2011, vol 37, no 3 
$y$ - and $z$-axes was calculated:

equation 1

$a_{h v}\left(W_{h i}\right)=\sqrt{a_{h x\left(W_{h i}\right)}^{2}+a_{h y\left(W_{h i}\right)}^{2}+a_{h z\left(W_{h i}\right)}^{2}} \quad\left(m s^{-2} r m s\right)$

To evaluate daily exposure duration to vibration, supervisors directly observed exposure patterns at the workplace over an entire week period. They used a stopwatch method and recorded the contact time the hands of the operators were actually exposed to the vibration from the tools.

Daily exposure durations to vibratory tools were calculated as those at the time of the study (for the workers without vascular disturbances) or those at the time of the onset of symptoms (for the subjects who reported white finger).

Daily vibration exposure was evaluated according to international standard ISO 53491-1 (1) and the European Directive on mechanical vibration (18), and expressed in terms of 8-hour frequency-weighted energy-equivalent rms acceleration magnitude $\left(A(8) W_{\mathrm{hi}}\right)$ :

$$
A(8) W_{h i}=\sqrt{\frac{1}{T_{0}} \sum_{i=1}^{n}\left(a_{h v i}\left(W_{h i}\right)\right)^{2} T_{i}} \quad\left(m s^{-2} r m s\right)
$$

where $a_{h v i}\left(W_{\text {hi }}\right)$ is the vibration total value (frequency weighted with $W_{\mathrm{h}}, W_{\mathrm{h}-\mathrm{bl}}, W_{\mathrm{hf}}$, or $W_{\mathrm{hT}}$ ) for tool $i$ in $\mathrm{ms}^{-2}$ rms, $T_{i}$ is the daily duration of exposure to tool $i$ in hours, and $T_{0}$ is the reference duration of 8 hours.

\section{Statistical analysis}

The statistical analysis of data was performed with the Stata software, version 11.0 (StataCorp LP, College Station, TX, USA). Continuous variables were summarized with the median as a measure of central tendency and quartiles or range as measures of dispersion. Comparisons between paired or unpaired data and correlations between variables were carried out by means of nonparametric statistics.

The relations of VWF incidence (binary outcome) to alternative measures of vibration exposure were assessed by the generalized estimating equations (GEE) method (logit link) to account for the within-subject dependency of the observations over time (19). Odds ratios (OR) and $95 \%$ confidence intervals $(95 \% \mathrm{CI})$ were estimated from the GEE logistic regression coefficients and their robust standard errors.

The "quasi-likelihood under the independence model criterion" (QIC), a modification of the Akaike's Information Criterion (AIC), as well as the "trace" component of
QIC statistic (20), were used to select the best working correlation structure in GEE analyses and compare the fit of GEE longitudinal models including alternative measures of daily vibration exposure $(21,22)$. In this study, an autoregressive correlation structure was specified for parameter estimation in GEE analyses since the QIC/trace statistics for this structure had smaller values than those obtained with different working correlations (eg, exchangeable, unstructured, or independent structures). The model with the smallest QIC value was also chosen as the best-fitting model for the relation between VWF and vibration exposure. To aid comparison, a $\Delta$ QIC was calculated as the difference between the QIC values for a specific exposure model and the model including $A(8)$ calculated with frequency weighting $W_{\mathrm{h}}$ (ie, the ISO weighting method). Although fit statistics for GEE models are still under active research (20), guidelines for selecting the best-fitting model may be borrowed from the strength of evidence rules developed for the AIC method (23): a $\Delta$ QIC $\leq 2$ suggests no difference in the fit between models, $4 \leq \Delta \mathrm{QIC} \leq 7$ tends to give support for the model with the smaller QIC, $\Delta$ QIC $>10$ means that the model with the smaller QIC provides a substantially better fit to the data.

\section{Results}

\section{Frequency-weighted rms acceleration magnitudes}

Table 1 reports the median values of tool rms acceleration magnitudes weighted by means of the four candidate frequency weightings. Overall, the following rank order for the machine rms acceleration values was observed: $a_{\mathrm{hv}}\left(W_{\mathrm{h}-\mathrm{bl}}\right)>a_{\mathrm{hv}}\left(W_{\mathrm{hf}}\right)>a_{\mathrm{hv}}\left(W_{\mathrm{hT}}\right)>a_{\mathrm{hv}}\left(W_{\mathrm{h}}\right)$ (Friedman's test for paired data: $\mathrm{P}<0.001)$. These findings were expected since the ISO frequency weighting $W_{\mathrm{h}}$ produces stronger attenuation of vibration acceleration with intermediate or high frequency components than the other frequency weightings. The greater magnitudes for $a_{\mathrm{hv}}\left(W_{\mathrm{h}-\mathrm{bl}}\right)$, compared with $a_{\mathrm{hv}}\left(W_{\mathrm{hf}}\right)$ and $a_{\mathrm{hv}}\left(W_{\mathrm{hT}}\right)$, are likely to depend on the different attenuation provided by these frequency weightings for vibration with frequencies $<25-50 \mathrm{~Hz}$ or $>200-400 \mathrm{~Hz}$ (figure 1). The correlations between alternative frequency-weighted rms accelerations were strong for $a_{\mathrm{hv}}\left(W_{\mathrm{h}-\mathrm{bl}}\right)$ versus $a_{\mathrm{hv}}\left(W_{\mathrm{hf}}\right)$ or $a_{\mathrm{hv}}\left(W_{\mathrm{hT}}\right)$ (Kendall's tau $\left.0.90-0.92\right)$ and very strong for $a_{\mathrm{hv}}\left(W_{\mathrm{hf}}\right)$ versus $a_{\mathrm{hv}}\left(W_{\mathrm{hT}}\right)$ (tau 0.98$)$, while poorer rank correlation coefficients were obtained for $a_{\mathrm{hv}}\left(W_{\mathrm{h}}\right)$ versus rms accelerations weighted with the other alternative frequency weightings (tau 0.27-0.34) (table 2).

Daily vibration exposure in terms of alternative measures of $A(8) W_{\mathrm{hi}}$ and exposure duration were significantly greater among the stone than forestry workers (table 3 ). 
Table 1. Median values of the root-sum-of-squares (vibration total value, $a_{\mathrm{hv}}$ ) of the root-mean-square (rms) acceleration magnitudes generated by the vibratory tools of this study. Acceleration magnitudes are weighted by means of the four candidate frequency weightings $\left(W_{\mathrm{h}}, W_{\mathrm{h}-\mathrm{b}}, W_{\mathrm{hf}}, W_{\mathrm{hT}}\right)$ displayed in figure 1.

\begin{tabular}{|c|c|c|c|c|c|c|c|c|c|}
\hline \multirow[t]{2}{*}{ Tools } & \multirow[t]{2}{*}{$N$} & \multicolumn{2}{|c|}{$a_{\mathrm{hv}}\left(W_{\mathrm{h}}\right)\left(\mathrm{ms}^{-2} \mathrm{rms}\right)$} & \multicolumn{2}{|c|}{$a_{\mathrm{hv}}\left(W_{\mathrm{h}-\mathrm{bl}}\right)\left(\mathrm{ms}^{-2} \mathrm{rms}\right)$} & \multicolumn{2}{|c|}{$a_{\mathrm{hv}}\left(W_{\mathrm{hf}}\right)\left(\mathrm{ms}^{-2} \mathrm{rms}\right)$} & \multicolumn{2}{|c|}{$a_{\mathrm{nv}}\left(W_{\mathrm{hT}}\right)\left(\mathrm{ms}^{-2} \mathrm{rms}\right)$} \\
\hline & & Median & Range & Median & Range & Median & Range & Median & Range \\
\hline Chainsaw & 23 & 5.2 & $2.9-9.2$ & 31.7 & $19.5-64.1$ & 31.5 & $19.4-63.8$ & 28.4 & $17.4-57.3$ \\
\hline Brush saw & 5 & 4.4 & $3.1-9.7$ & 27.3 & $18.2-40.5$ & 25.9 & $17.2-38.5$ & 24.3 & $16.2-36.1$ \\
\hline Grinder & 7 & 4.2 & $1.0-5.9$ & 60.8 & $14.0-95.5$ & 47.0 & $8.4-57.2$ & 43.1 & $7.7-52.4$ \\
\hline Straight stone hammer & 4 & 17.1 & $9.0-23.1$ & 200 & 130-282 & 163 & $100-234$ & 152 & $91-217$ \\
\hline
\end{tabular}

Table 2. Kendall's rank correlation coefficients between root-mean-square (rms) acceleration magnitudes generated by the vibratory tools of this study $(\mathrm{N}=39)$. The rms acceleration magnitudes $\left(a_{\mathrm{hv}}\right)$ are weighted according to the four candidate frequency weightings $\left(W_{\mathrm{h}}, W_{\mathrm{h}-\mathrm{b}}, W_{\mathrm{hf}}, W_{\mathrm{hT}}\right)$ displayed in Figure 1.

\begin{tabular}{|c|c|c|c|c|}
\hline $\begin{array}{l}\text { Frequency weighted rms } \\
\text { acceleration }\end{array}$ & $a_{\mathrm{hv}}\left(W_{\mathrm{h}}\right)$ & $a_{\text {hv }}\left(W_{\text {h-bl }}\right)$ & $a_{\mathrm{hv}}\left(W_{\mathrm{hf}}\right)$ & $a_{\text {hv }}\left(W_{\text {hT }}\right)$ \\
\hline$a_{\mathrm{hv}}\left(W_{\mathrm{h}}\right)$ & 1.0 & . & . & . \\
\hline$a_{\mathrm{hv}}\left(W_{\mathrm{h}-\mathrm{bl}}\right)$ & 0.273 & 1.0 & . & . \\
\hline$a_{\mathrm{hv}}\left(W_{\mathrm{hf}}\right)$ & $0.337^{a}$ & $0.905^{b}$ & 1.0 & . \\
\hline$\underline{a_{\mathrm{hv}}\left(W_{\mathrm{hT}}\right)}$ & $0.320^{\mathrm{a}}$ & $0.922^{b}$ & $0.983^{b}$ & 1.0 \\
\hline
\end{tabular}

a $\mathrm{P}<0.05$ (Bonferroni adjusted).

b $\mathrm{P}<0.001$ (Bonferroni adjusted)

Table 3. Daily vibration exposure in the vibration-exposed workers not affected with vibration-induced white finger (VWF) at baseline. See text for the definitions of $A(8) W_{\mathrm{h}}, A(8) W_{\mathrm{h}-\mathrm{b}}, A(8) W_{\mathrm{hf}}$, and $A(8) W_{\mathrm{h} \text {. }}$

\begin{tabular}{|c|c|c|c|c|}
\hline \multirow[t]{3}{*}{ Vibration exposure } & \multicolumn{4}{|c|}{ Vibration-exposed workers } \\
\hline & \multicolumn{2}{|c|}{ Forestry workers $(\mathrm{N}=185)$} & \multicolumn{2}{|c|}{ Stone workers $(\mathrm{N}=21)$} \\
\hline & Median & Quartile & Median $^{a}$ & Quartile \\
\hline Duration of daily exposure (minutes) & 123 & 63-169 & 346 & $286-423$ \\
\hline$A(8) W_{\mathrm{h}}\left(\mathrm{ms}^{-2} \mathrm{rms}\right)$ & 3.4 & $2.5-4.5$ & 6.4 & $5.1-9.6$ \\
\hline$A(8) W_{\mathrm{n}-\mathrm{bl}}\left(\mathrm{ms}^{-2} \mathrm{rms}\right)$ & 18.5 & $13.2-26.0$ & 88.6 & $74.0-125$ \\
\hline$A(8) W_{\mathrm{hf}}\left(\mathrm{ms}^{-2} \mathrm{rms}\right)$ & 17.8 & $12.8-24.8$ & 73.5 & 61.4-104 \\
\hline$A(8) W_{\mathrm{hT}}\left(\mathrm{ms}^{-2} \mathrm{rms}\right)$ & 16.1 & $11.6-22.3$ & 68.2 & $57.0-96.2$ \\
\hline
\end{tabular}

a $\mathrm{P}<0.0001$ (Mann-Whitney test).

Incidence of vibration-induced white finger

In the cross-sectional study, the point prevalence of VWF was $17.3 \%$ (43/249) among the vibration-exposed workers who participated in the follow-up. According to job title, VWF prevalence was $14.0 \%(30 / 215)$ and $38.2 \%(13 / 34)$ among the forestry and stone workers, respectively. Over the follow-up period, there were 11 new cases of VWF, giving a three-year incidence of $5.3 \%$ [11/(249-43)]. The cumulative incidence of VWF was $4.3 \%[8 /(215-30)]$ and $14.3 \%$ [3/(34-13)] among the forestry and stone workers, respectively.

\section{VWF and alternative measures of vibration exposure}

Table 4 reports the relations between the incidence of VWF and vibration exposure over the follow-up period. In general, all alternative measures of daily vibration exposure were significantly associated with an increased risk for VWF over time. The excess risk for VWF varied from $15-19 \%$ per unit increase in daily vibration exposure $\left[1 \mathrm{~ms}^{-2}\right.$ for $A(8) W_{\mathrm{h}}$ and $10 \mathrm{~ms}^{-2}$ for $A(8) W_{\mathrm{h}-\mathrm{bl}}, A(8) W_{\mathrm{hf}}$, and $\left.A(8) W_{\mathrm{hT}}\right]$. Duration of exposure was also a significant predictor of VWF (OR 2.0 per year of follow-up). The magnitude of the QIC statistic and the $\triangle \mathrm{QIC}$ values suggested that the model including $A(8) W_{\text {h-bl }}$ provided a better fit to the data than the other alternative measures of daily vibration exposure $(\Delta \mathrm{QIC}$ 6-14). Moreover, the QIC statistic tended to give more support to models with $A(8) W_{\mathrm{hf}}(\Delta \mathrm{QIC} 6)$ or $A(8) W_{\mathrm{hT}}$ ( $\triangle$ QIC 8 ) as predictors for VWF than that with $A(8) W_{\mathrm{h}}$. The difference between $A(8) W_{\mathrm{hf}}$ and $A(8) W_{\mathrm{hT}}$ models was negligible ( $\triangle$ QIC 2$)$.

Table 5 compares the observed incidence of VWF in the vibration-exposed workers with those predicted by the alternative measures of daily vibration exposure 
Table 4. Odds ratios $(\mathrm{OR})$ and robust $95 \%$ confidence intervals $(95 \% \mathrm{CI})$ for the association between the cumulative incidence of vibration-induced white finger (VWF) (medical interview assisted by color charts) and alternative measures of daily vibration exposure expressed in terms of 8-hour frequency-weighted energy-equivalent root-mean-square ( $r m s)$ acceleration $[A(8)]$. $A(8)$ was calculated by weighting the tool rms acceleration magnitudes according to the four candidate frequency weightings $\left(W_{\mathrm{h}}, W_{\mathrm{h}-\mathrm{bl}}, W_{\mathrm{h} f}, W_{\mathrm{hT}}\right)$ displayed in figure 1. The $\mathrm{OR}$ and $95 \% \mathrm{CI}$ were estimated by the generalized estimating equations (GEE) method. In the logistic models, the measures of vibration exposure are included as continuous variables. The Wald test for the measures of vibration exposure, and the quasi-likelihood under the independence model criterion for the comparison between models (QIC) are given.

\begin{tabular}{|c|c|c|c|c|c|c|}
\hline Predictors & $\mathrm{OR}$ & $95 \% \mathrm{Cl}$ & Wald test & $P$ & QIC & $\Delta Q \mid C$ \\
\hline$A(8) W_{\mathrm{h}}\left(\mathrm{ms}^{-2} \mathrm{rms}\right)$ & 1.19 & $1.03-1.37$ & 5.62 & 0.018 & 1198 & 0 \\
\hline Years of follow up (y) & 2.07 & $1.52-2.82$ & 21.6 & $<0.001$ & & \\
\hline$A(8) W_{\text {h-bl }}\left(\times 10 \mathrm{~ms}^{-2} \mathrm{rms}\right)$ & 1.15 & $1.03-1.28$ & 5.71 & 0.017 & 1184 & -14 \\
\hline Years of follow up (y) & 2.05 & $1.50-2.80$ & 20.5 & $<0.001$ & & \\
\hline$A(8) W_{\mathrm{hf}}\left(\times 10 \mathrm{~ms}^{-2} \mathrm{rms}\right)$ & 1.17 & $1.01-1.34$ & 4.58 & 0.032 & 1192 & -6 \\
\hline Years of follow up (y) & 2.05 & $1.51-2.78$ & 21.1 & $<0.001$ & & \\
\hline$A(8) W_{\mathrm{hT}}\left(\times 10 \mathrm{~ms}^{-2} \mathrm{rms}\right)$ & 1.18 & $1.02-1.38$ & 4.80 & 0.029 & 1190 & -8 \\
\hline Years of follow up (y) & 2.05 & $1.51-2.78$ & 21.0 & $<0.001$ & & \\
\hline
\end{tabular}

Table 5. Observed and predicted cumulative incidence of vibration-induced white finger (VWF) (medical interview assisted by color charts) among vibration-exposed workers by job title and alternative measures of daily vibration exposure in terms of 8-hour energyequivalent acceleration magnitude $[A(8)] . A(8)$ was calculated by weighting the tool root-mean-square (rms) acceleration magnitudes according to the four candidate frequency weightings $\left(W_{h}, W_{h-b l}, W_{h f}, W_{h T}\right)$ displayed in figure 1 . The predicted incidence of VWF is estimated by the generalized estimating equations (GEE) method (see models in table 3).

\begin{tabular}{lcccrr}
\hline Job title & $\begin{array}{c}\text { Observed VWF } \\
\text { incidence } \\
\end{array}$ & & \multicolumn{3}{c}{ Predicted VWF incidence (\%) } \\
\cline { 3 - 6 } & 4.3 & $A(8) W_{\mathrm{h}}$ & $A(8) W_{\mathrm{h}-\mathrm{bl}}$ & $A(8) W_{\mathrm{hf}}$ & $A(8) W_{\mathrm{hT}}$ \\
\hline Forestry workers & 14.3 & 5.4 & 5.0 & 5.1 & 5.1 \\
Stone workers & 8 & 12 & 11 & 11 \\
\hline
\end{tabular}

(based on the models in table 4). There were minor discrepancies between the predictions of the various models $(5 \%)$ and the observed VWF incidence among the forestry workers (4\%). The $A(8) W_{\mathrm{h}}$ model tended to underestimate the incidence of VWF among the stone workers $(8 \%)$, while the alternative models provided a better prediction of the outcome [observed incidence $14 \%$ versus predicted incidence $12 \%$ for $A(8) W_{\mathrm{h}-b l}$ and $11 \%$ for $A(8) W_{\mathrm{hf}}$ or $A(8) W_{\mathrm{hT}} \mathrm{T}$.

\section{Discussion}

\section{Frequency weightings for hand-transmitted vibration}

The characteristics of the ISO frequency weighting for hand-transmitted vibration have been established since the late 1970s. The ISO weighting curve was incorporated in the $1^{\text {st }}$ edition of the international standard ISO 5349:1986 (24) and retained as the $W_{\mathrm{h}}$ frequency weighting in the current standard ISO 5349-1:2001 (1). Basically, the $W_{\mathrm{h}}$ weighting is derived from extrapolation of the findings of a laboratory study of subjective equal sensation contours as a function of vibration frequency $(3-300 \mathrm{~Hz})$ applied to the hands of a small number of healthy subjects (25).
Over the working frequency range specified in ISO 5349-1 $(6.3-1250 \mathrm{~Hz})$, the shape of the standardized weighting curve assumes that the sensitivity of the finger-handarm system to vibration is approximately proportional to vibration acceleration $<16 \mathrm{~Hz}$ and decreases in inverse proportion to frequency from $16-1250 \mathrm{~Hz}$. Thus, the ISO frequency weighting assumes that low frequency acceleration has more importance for adverse health effects than intermediate and high frequency acceleration. It has been argued that there is poor experimental or epidemiological evidence for this assumption and that a frequency weighting based on vibration sensation in the human hand may be unsuitable for the assessment of chronic upper-limb disorders provoked by hand-transmitted vibration, including $\operatorname{VWF}(26,27)$.

Physiological studies of the acute response of finger circulation to hand-transmitted vibration have shown that vibration with frequencies of $31.5-250 \mathrm{~Hz}$ induced more powerful vasoconstriction in both vibrated and non-vibrated fingers than vibration with a frequency of $16 \mathrm{~Hz}$ at the same weighted rms acceleration magnitude, suggesting that the ISO frequency weighting may overestimate the vascular effects of low frequency vibration (7).

The results of biodynamic investigations have also questioned the suitability of the ISO frequency weighting for assessing the severity of hand-transmitted vibra- 
tion exposure. Using a method to analyze vibration power absorption in the fingers, Dong et al (9) concluded that the current standardized frequency weighting could overestimate the effects of low frequency vibration and greatly underestimate the high frequency effects, mainly those associated with the vascular and neurological components of the hand-arm vibration syndrome. Moreover, these authors found that, for many vibratory tools, vibration power absorption of the fingers correlated much better with unweighted than ISO-weighted acceleration. These findings resulted in a recent proposal for a new frequency weighting for handtransmitted vibration based on vibration power absorption of the fingers (called $W_{\mathrm{hf}}$ in this study) $(9,10)$.

In the past, several epidemiological studies of crosssectional type showed that the ISO-weighting method overestimated the risk of VWF among users of machines with low frequency vibration such as sand rammers or other percussive tools, while underestimation of VWF was observed among workers exposed to vibration containing high frequency components $(3-6,13)$. As suggested by some epidemiological studies $(12,13,26$, 27 ), unweighted rms acceleration might be more appropriate for evaluating the severity of hand-transmitted vibration. In a Japanese study of worker groups using a great variety of vibratory tools, Tominaga (13) found that high frequency vibration had a strong influence on the occurrence of vascular symptoms and proposed a new frequency weighting (called $W_{\mathrm{hT}}$ in this study) to improve the exposure-response relationship for VWF in the study population $(10,13)$.

\section{Alternative exposure-response relationships for VWF}

In this prospective cohort study, the four candidate frequency weightings $W_{\mathrm{h}}, W_{\mathrm{h}-\mathrm{bl}}, W_{\mathrm{hf}}$, and $W_{\mathrm{h}} \mathrm{T}$ were used to construct alternative measures of daily vibration exposure expressed as $A(8)$ in accordance with ISO 5349-1 (1). It should be noted that $A(8)$ is a measure of daily "energy equivalent" acceleration that assumes a second power time dependency over a typical work day (ie, $a_{i}^{2} t_{i}$ ). Some authors have questioned the appropriateness of a second power time dependency to evaluate vibration exposure, but this subject is beyond the scope of this paper $(26,28)$.

In this study, we assumed that the physical characteristics of vibration (ie, magnitude, frequency, and direction) and the duration of exposure were the major determinants of the vascular effects of handtransmitted vibration. We recognize that there are other factors, not included in the models of this study, that may have potential effects on the development of VWF such as the gripping and pushing forces applied by the hands of the tool operators and the points of contact (fingers or hand) with the source of vibration (1). Unfortunately, there are no currently standardized methods to measure coupling forces; the extent to which the dose-response relationship for VWF may be influenced by these factors could be not determined in our sample of vibration-exposed workers.

In this study, data analysis with a GEE-logistic model showed that measures of vibration exposure that give more weight to intermediate and high-frequency vibration fitted the VWF outcome better than a measure derived from the ISO frequency weighting. Moreover, a measure of statistical fit gave more support to the model including $A(8) W_{\mathrm{h}-b l}$ rather than $A(8) W_{\mathrm{hf}}$ or $A(8) W_{\mathrm{hT}}$, even though GEE models gave rise to similar predictions for VWF. The high correlation between $a_{\mathrm{hv}}\left(W_{\mathrm{hf}}\right)$ and $a_{\mathrm{hv}}\left(W_{\mathrm{hT}}\right)$ and the output from data modeling suggest that the difference between $W_{\mathrm{hf}}$ and $W_{\mathrm{hT}}$ is too small to favor one of these two frequency weightings. It should be recognized, however, that selecting a model on the basis of a fit statistic does not always mean that the chosen model provides the most plausible interpretation of the occurrence of a health disorder.

In this study, the discrepancy in the predictions of VWF between the ISO weighting and the other alternative frequency weightings was small for the forestry workers but more substantial for the stone workers. These findings may be explained, at least partially, taking into account the differences in the frequency components of vibration spectra produced by the vibratory tools. Frequency analysis of tool vibration showed that the highest unweighted rms acceleration magnitudes for the chainsaws were detected between $100-200 \mathrm{~Hz}$, while low acceleration values were measured outside this frequency range (figure 2). Conversely, the stone hammers produced high-magnitude shocks containing energy over a wide range of intermediate and high frequency vibration (figure 3 ). Since the ISO $W_{\mathrm{h}}$ curve greatly reduces the contribution of high frequency vibration to the magnitude of frequency weighted acceleration, these frequency components are likely to play an important role in the onset of VWF disorders.

The VIBRISKS study is the first of its kind in which the exposure-response relationship for VWF has been investigated by means of incidence data. Our findings tend to support those of biodynamic and physiological studies suggesting that, over the frequency range of vibration measurement required by the ISO standard $(6.3-1250 \mathrm{~Hz})$, greater importance should be given to vibration frequencies $\geq 20 \mathrm{~Hz}$. In addition, the VIBRISKS incidence study strengthens the conclusions of previous cross-sectional surveys showing that measures of daily or cumulative vibration dose derived from unweighted rms acceleration were better predictors of the occurrence of VWF than equivalent doses calculated from ISO-weighted acceleration (27).

In our previous longitudinal studies of the VIBRISKS research project, we found significant associations 

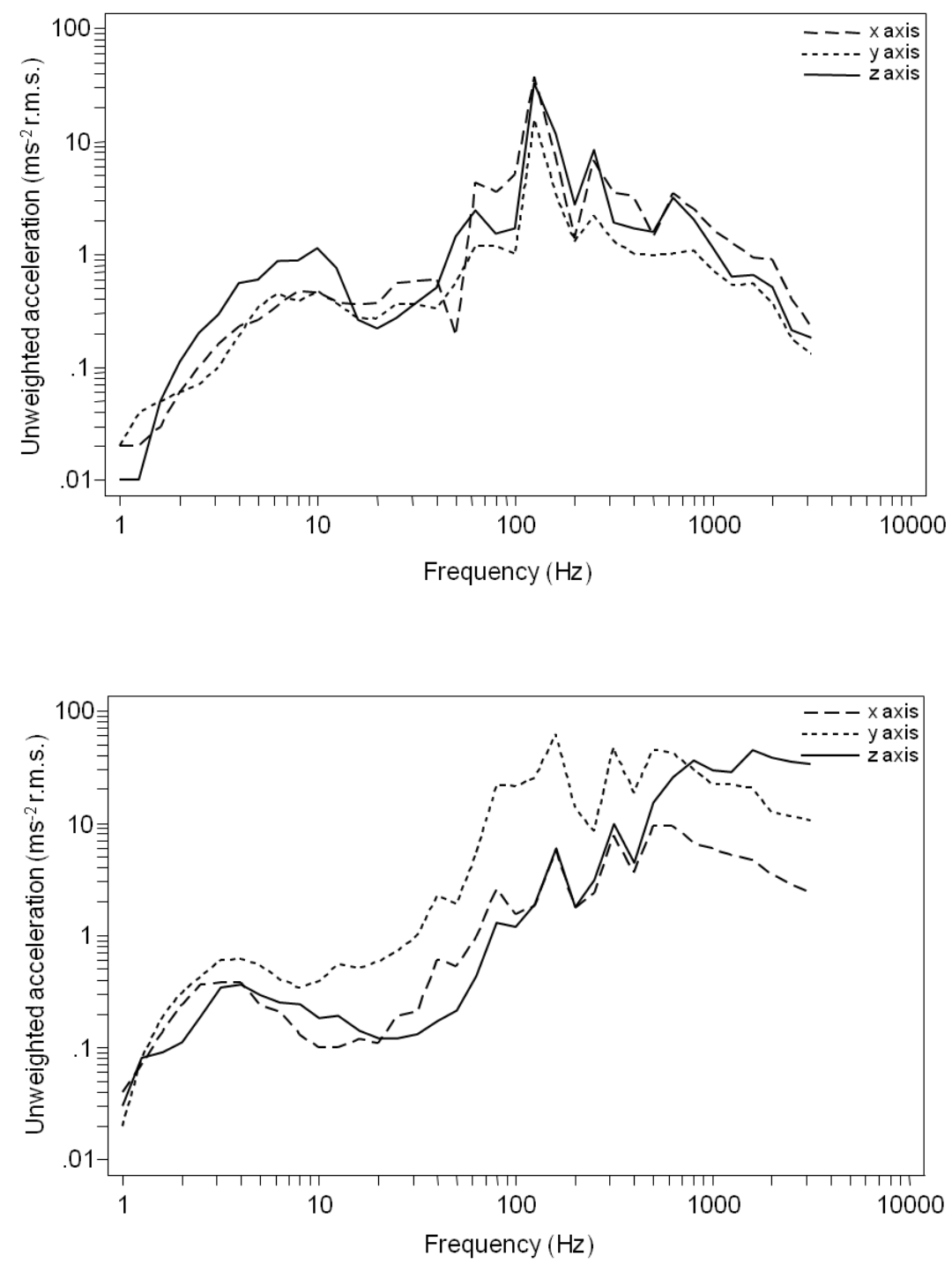

Figure 2. One-third octave band acceleration spectra in the $x$-, $y$ - and $z$-axes for a chainsaw. Weighted acceleration magnitudes according to the alternative frequency weightings: $a_{\mathrm{hv}}\left(W_{\mathrm{h}}\right)=7.4 \mathrm{~ms}^{-2} \mathrm{rms}$; $a_{\text {hv }}\left(W_{\text {h-bl }}\right)=56.4 \mathrm{~ms}^{-2} \mathrm{rms} ; a_{\text {hv }}\left(W_{\text {hf }}\right)=57.5$ $\mathrm{ms}^{-2} \mathrm{rms} ; \mathrm{a}_{\mathrm{hv}}\left(W_{\mathrm{hT}}\right)=52.8 \mathrm{~ms}^{-2} \mathrm{rms}$.
Figure 3. One-third octave band acceleration spectra in the $x-, y$ - and $z$-axes for a straight stone hammer. Weighted acceleration magnitudes according to the alternative frequency weightings: $a_{\mathrm{hv}}\left(W_{\mathrm{h}}\right)=9.9 \mathrm{~ms}^{-2} \mathrm{rms} ; \mathrm{a}_{\mathrm{hv}}\left(W_{\mathrm{h}-\mathrm{bl}}\right)=134 \mathrm{~ms}^{-2}$ $\mathrm{rms} ; a_{\mathrm{hv}}\left(W_{\mathrm{hf}}\right)=102 \mathrm{~ms}^{-2} \mathrm{rms} ; a_{\mathrm{hv}}\left(W_{\mathrm{hT}}\right)=94.0$ $\mathrm{ms}^{-2} \mathrm{rms}$ between VWF and some predictors such as age at entry, body mass index, or smoking $(11,12)$. However, the difference in the OR estimates for $A(8) W_{\text {hi }}$ between the models of this study and multivariable models including additional predictors was $<10 \%$. Therefore, we chose to present simpler exposure-response relationships for VWF to make them comparable with the predictive model recommended in annex C to ISO 5349-1 (1).

There are other limitations in this study that deserve attention. Vibration measurements were made on the tools currently used by the forestry and stone workers and this may be a source of uncertainty for the estimation of vibration exposure over time. It should be noted, however, that all forestry operators had work experience limited to anti-vibration chainsaws and the vibration emission from the pneumatic tools used by the stone workers has been found fairly similar over time (3). Thus, the rms acceleration magnitude of vibration measured in the tools of the present study may be considered representative of the lifetime exposure of the study population.

Another limitation of this study is the duration of the follow-up time. It is known that VWF symptoms may have latency of several years while the cohort of this study was followed for a rather short period (three years). We recognize this limitation, which was mainly due to constraints of the human and financial resources available for the VIBRISKS project, but the results of previous pathophysiological, biodynamic, and epidemiological studies tend to support our findings that improvements are possible to the frequency weighting used to predict the development of VWF in current standards.

Other potential sources of bias for this longitudinal study (ie, vibration measurement with a rms averaging procedure, quantification of duration of daily exposure to hand-transmitted vibration, and pattern of missing data) have been discussed in detail elsewhere $(11,12)$. 


\section{Evidence for improving frequency weighting}

The hand-arm vibration syndrome includes vascular, sensorineural, and osteoarticular disorders $(4,29)$. This study focused on the relation between VWF and alternative frequency weightings for hand-transmitted vibration. Our findings suggest that frequency weightings that give more importance to intermediate and high frequency vibration are associated with more accurate predictions of VWF incidence than obtained with the current ISO frequency weighting $W_{\mathrm{h}}$. It is possible that these findings may be valid also for vibration-induced sensory disorders in the fingers since experimental studies have shown that acute exposures to vibration with frequency of $125-500 \mathrm{~Hz}$ caused the highest temporary threshold shifts in fingertip vibrotactile perception (30). Several cross-sectional studies have found an increased prevalence of finger sensory dysfunction among subjects exposed to high frequency vibration such as dentists and dental hygienists, although no clear exposure-response relationship for sensory disorders has been outlined so far $(4,31,32)$. An excess risk for bone and joint disorders in the upper limbs has been found among workers exposed to low frequency vibration $(<50 \mathrm{~Hz})$ of high magnitude from percussive tools $(4,29)$. It is believed that, in addition to vibration, the ergonomic stressors associated with work with heavy tools (eg, excessive physical effort, awkward postures) may play a role in the pathogenesis of these disorders. Since it is hard to differentiate the independent contributions of mechanical and ergonomic risk factors for the development of bone and joint injuries, no dose-response relationship, even tentatively, has yet to be established.

These considerations suggest that the frequency of vibration is a strong determinant for the mechanisms of injury among vibration-exposed workers. In ISO $5349-1$, it is said that the frequency weighting $W_{\mathrm{h}}$ is used to assess all biological effects of hand-transmitted vibration, but the findings of biodynamic, physiological, and epidemiological studies suggest that it is unlikely that one frequency weighting may be appropriate to cover all adverse health effects (ie, vascular, neurological, osteoarticular) associated with vibration exposure. In Germany, for instance, the VDI (Verein Deutscher Ingenieure) 2057-part 2 guidelines assume an increased risk for bone and joint disorders when the proportion of weighted acceleration $<50 \mathrm{~Hz}$ is $>75 \%$ of the total $W_{\mathrm{h}}$ weighting, while peripheral sensorineural and vascular disturbances may be expected when such a proportion comes to vibration with frequencies $>50 \mathrm{~Hz}$ (33).

One argument for retaining the $W_{\mathrm{h}}$ curve is the large amount of vibration and health data collected so far with the current ISO weighting method. Other arguments are the possible implications that a change in $W_{\mathrm{h}}$ may have for employers who must manage the provisions of the $\mathrm{EU}$ Directive on mechanical vibration and for designers and manufacturers of tools, work equipment, and personal protective equipment (34). We recognize that these arguments are reasonable and deserve attention, but the results of this and other cross-sectional and longitudinal studies suggest that there is sufficient epidemiological evidence for giving more weight to intermediate and high frequency vibration to evaluate the severity of hand-transmitted vibration, at least for the vascular and possibly the neurological component of the hand-arm vibration syndrome.

These findings, in addition to those provided by biodynamic and physiological studies of the frequencydependent effects of vibration, can lead to a better understanding of the exposure-response relationships for vibration-induced health disorders and contribute to an improvement or change in the vibration frequency weighting currently recommended by the international standard ISO 5349-1.

\section{Acknowledgements}

The authors would like to acknowledge the valuable contribution of the occupational health personnel of the National Health Service and the University of Trieste, as well as that of the employers and employees of the surveyed companies, who made it possible to carry out this epidemiological study. The comments on and suggestions for the manuscript provided by Professor Michael J Griffin (ISVR, University of Southampton, UK) are gratefully acknowledged. This research was supported by the European Commission under the Quality of Life and Management of Living Resources program - Project No. QLK4-2002-02650 (VIBRISKS). The authors declare no competing interests.

\section{References}

1. International Organization for Standardization (ISO). Mechanical vibration - measurement and evaluation of human exposure to hand-transmitted vibration, part 1: general requirements. Geneva: ISO; 2001. ISO 5349-1.

2. Barregard L, Ehrenström L, Marcus K. Hand-arm vibration syndrome in Swedish car mechanics. Occup Environ Med. 2003;60:287-94. doi:10.1136/oem.60.4.287.

3. Bovenzi M, and the Italian Study Group on Physical Hazards in the Stone Industry. Hand-arm vibration and dose-response relation for vibration induced white finger among quarry drillers and stone carvers. Occup Environ Med. 1994;51:60311. doi:10.1136/oem.51.9.603.

4. Bovenzi M. Exposure-response relationship in the hand-arm vibration syndrome: an overview of current epidemiology research. Int Arch Occup Environ Health. 1998;71:509-19. doi:10.1007/s004200050316. 
5. Dandanell R, Engström K. Vibration from riveting tools in the frequency range $6 \mathrm{~Hz}-10 \mathrm{MHz}$ and Raynaud's phenomenon. Scand J Work Environ Health. 1986;12:338-42.

6. Engström K, Dandanell R. Exposure conditions and Raynaud's phenomenon among riveters in the aircraft industry. Scand J Work Environ Health. 1986;12:293-5.

7. Bovenzi M, Lindsell CJ, Griffin MJ. Acute vascular response to the frequency of vibration transmitted to the hand. Occup Environ Med. 2000;57:422-30. doi:10.1136/oem.57.6.422.

8. Dong RG, Welcome DE, Wu JZ. Frequency weightings based on biodynamics of fingers-hand-arm system. Ind Health. 2005;43:516-26. doi:10.2486/indhealth.43.516.

9. Dong JH, Dong RG, Rakheja S, Welcome DE, McDowell TW, Wu JZ. A method for analyzing absorbed power distribution in the hand and arm substructures when operating vibrating tools. J Sound Vib. 2008;311:1286-304. doi:10.1016/j. jsv.2007.10.031.

10. Pitts P. Evaluation of candidates for additional frequency weightings for hand-arm vibration measurement. Humanschwingungen. VDI-Berichte Nr 2097. Würzburg: VDI Verlag; 2010. p125-34.

11. Bovenzi M. A prospective cohort study of exposure-response relationship for vibration-induced white finger. Occup Environ Med. 2010;67:38-46. doi:10.1136/oem.2009.046128.

12. Bovenzi M. A longitudinal study of vibration white finger, cold response of digital arteries, and measures of daily vibration exposure. Int Arch Occup Environ Health 2010; 83:259-72. doi:10.1007/s00420-009-0461-2.

13. Tominaga Y. New frequency weighting of hand-arm vibration. Ind Health 2005;43:509-15. doi:10.2486/indhealth.43.509.

14. Humanvibration.com [homepage on the Internet]. Southampton (United Kingdom): Human Factors Research Unit, Institute of Sound and Vibration Research, University of Southampton [updated 28 February 2007; cited 8 May 2008]. Available from: http://www.vibrisks.soton.ac.uk.

15. Negro C, Rui F, D’Agostin F, Bovenzi M. Use of color charts for the diagnosis of finger whiteness in vibration-exposed workers. Int Arch Occup Environ Health. 2008;81:633-8. doi:10.1007/s00420-007-0248-2.

16. Olsen N, Hagberg M, Ekenvall L, Futatsuka M, Harrison J, Nasu Y, et al. Clinical and laboratory diagnostics of vascular symptoms induced by hand-arm vibration: report from discussions in a working group. Stockholm: Arbetarskyddsverket; 1995. Arbete och Hälsa, volume 5, p.181-6.

17. International Organization for Standardization (ISO). Human response to vibration - measuring instrumentation. Geneva: ISO; 2005. ISO 8041.

18. Directive 2002/44/EC of the European Parliament and the Council of 25 June 2002 on the minimum health and safety requirements regarding the exposure of workers to the risks arising from physical agents (vibration) (16th individual Directive within the meaning of Article 16(1) of Directive 89/391/EEC). Off J Eur Communities. L 117/13; 6.7.2002.
19. Diggle PJ, Heagerty PJ, Liang K-Y, Zeger SL. Analysis of longitudinal data. New York: Oxford University Press; 2002.

20. Hilbe JM. Logistic regression models. Boca Raton, FL: Chapman \& Hall/CRC Press; 2009.

21. Pan W. Akaike's information criterion in generalized estimating equations. Biometrics. 2001;57:120-5. doi:10.1111/j.0006341X.2001.00120.x.

22. Cui J. QIC program and model selection in GEE analyses. Stata J. 2007;7:209-20.

23. Burnham KP, Anderson DR. Multimodel inference: understanding AIC and BIC in model selection. Sociol Methods Res. 2004;33:261-304. doi:10.1177/0049124104268644.

24. International Organization for Standardization (ISO). Mechanical vibration - guidelines for the measurement and the assessment of human exposure to hand-transmitted vibration. Geneva: ISO; 1986. ISO 5349.

25. Miwa T. Evaluation methods for vibration effect. Part 3: Measurement of thresholds and equal sensation contours on hand for vertical and horizontal vibrations. Ind Health. 1967;5:213-20. doi:10.2486/indhealth.5.213.

26. Griffin MJ. Measurement, evaluation, and assessment of occupational exposures to hand-transmitted vibration. Occup Environ Med. 1997;54:73-89. doi:10.1136/oem.54.2.73.

27. Griffin MJ, Bovenzi M, Nelson CM. Dose-response patterns for vibration-induced white finger. Occup Environ Med. 2003;60:16-26. doi:10.1136/oem.60.1.16.

28. Bovenzi M, Lindsell CJ, Griffin MJ. Response of finger circulation to energy equivalent combinations of magnitude and duration of vibration. Occup Environ Med. 2001;58:185-93. doi:10.1136/oem.58.3.185.

29. Comité Européen de Normalisation [European Committee for Standardization]. Mechanical vibration - guide to the health effects of vibration on the human body. CR Report 12349 . Brussels: Comité Européen de Normalisation; 1996.

30. Harada N, Griffin MJ. Factors influencing vibration sense thresholds used to assess occupational exposure to handtransmitted vibration. Br J Ind Med. 1991;48:185-92.

31. Hjortsberg U, Rosén I, Ørbæk, Lundborg G, Balogh I. Finger receptor dysfunction in dental technicians exposed to high-frequency vibration. Scand J Work Environ Health. 1989;15:339-44.

32. Lundström R, Lindmark A. Effects of local vibration on tactile perception in the hands of dentists. J Low Freq Noise Vib. 1982;1:1-11.

33. Verein Deutscher Ingenieure (VDI) [The Association of German Engineers]. Human exposure to mechanical vibration - hand-arm vibration. VDI 2057-2. Düsseldorf: VDI; 2002.

34. Nelson CM. The standard frequency weighting for handtransmitted vibration: implications of a proposed revision. In Donati P, editor. Proceedings of the 9th International Conference on Hand-arm Vibration. Nancy: INRS. Note Scientifique \& Technique 2001;242:281-7.

Received for publication: 5 July 2010 